\title{
Biomarkers in persistent AF and heart failure: impact of catheter ablation compared with rate-control
}

Short title: Biomarkers after AF ablation in heart failure

David G Jones MD(Res) MRCP ${ }^{1,2}$, Shouvik K Haldar MD(Res) MRCP ${ }^{1,2}$, Jacqueline Donovan PhD

DipRCPath $^{3}$, Theresa A McDonagh MD FRCP ${ }^{2}$, Rakesh Sharma PhD MRCP ${ }^{2}$, Wajid Hussain $\mathrm{MRCP}^{1,2}$, Vias Markides MD FRCP ${ }^{1,2}$, Tom Wong MD FRCP ${ }^{1,2}$

Departments of Cardiac Electrophysiology ${ }^{1}$, Cardiology $^{2}$, and Clinical Biochemistry ${ }^{3}$

NIHR Cardiovascular Biomedical Research Unit

Royal Brompton \& Harefield NHS Foundation Trust,

Imperial College London

Financial disclosure: This work was supported by the NIHR cardiovascular Biomedical Research

Unit at the Royal Brompton and Harefield NHS Foundation Trust and Imperial College London.

Biomarker assay costs and research fellow grants for Dr Jones and Dr Haldar were supported by St

Jude Medical UK. The other authors declare no conflicts of interest.

Address for correspondence

Dr Tom Wong

Heart Rhythm Centre and NIHR Cardiovascular Biomedical Research Unit

Royal Brompton and Harefield NHS Foundation Trust

This article has been accepted for publication and undergone full peer review but has not been through the copyediting, typesetting, pagination and proofreading process, which may lead to differences between this version and the Version of Record. Please cite this article as doi: 10.1111/pace.12919.

This article is protected by copyright. All rights reserved. 
Sydney Street, London SW3 6NP United Kingdom

Facsimile: $+442073518634 \quad$ Telephone: +442073518619

Email: tom.wong@imperial.ac.uk

\section{Abstract}

\section{Background}

To investigate the effects of catheter-ablation and rate-control strategies on cardiac and inflammatory biomarkers in patients with heart failure and persistent atrial fibrillation (AF).

\section{Methods}

Patients were recruited from the ARC-HF trial (NCT00878384), which compared ablation with rate-control for persistent $\mathrm{AF}$ in heart failure. B-type natriuretic peptide (BNP), mid-regional pro-atrial natriuretic peptide(MRproANP), Apelin and Interleukin 6(IL-6) were assayed at baseline, 3, 6, and 12-months. The primary endpoint, analysed per-protocol, was change from baseline at 12-months.

\section{Results}

Of 52 recruited patients, 24 ablation and 25 rate-control subjects were followed to 12 months. After $1.2 \pm 0.5$ procedures, sinus rhythm was present in $22(92 \%)$ ablation patients; under rate-control, rate criteria were achieved in 23(96\%) of 24 patients remaining in AF. At 12 months, MR-proANP fell significantly in the ablation arm(-106.0pmol/L,IQR -228.2 to -60.6$)$ compared with rate-control( $-28.7 \mathrm{pmol} / \mathrm{L},-69$ to $+9.5, \mathrm{p}=0.028)$. BNP showed a similar trend towards reduction ( $\mathrm{p}=0.051$ ), with no significant difference in Apelin $(\mathrm{p}=0.13)$ or IL-6(p=0.68). Changes in MR-proANP and BNP correlated with peakVO2 and ejection fraction, and MRproANP additionally with quality-of-life score.

\section{Conclusions}

Catheter ablation, compared with rate-control, in patients with heart failure and persistent AF was associated with significant reduction in MR-proANP, which correlated with physiological and symptomatic improvement. Ablation-based rhythm-control may induce beneficial cardiac remodelling, unrelated to changes in 
inflammatory state. This may have prognostic implications, which require confirmation by event-endpoint studies.

Key Words

Atrial fibrillation; biomarkers; catheter ablation; heart failure; rate-control

\section{Introduction}

The optimal therapy for AF in heart failure remains unclear: drug-based 'rhythm-control' has been shown to have no clear advantage over drug-based 'rate-control'. ${ }^{1}$ Radiofrequency catheter ablation has been shown to be successful in restoring sinus rhythm in patients with heart failure and to confer clinical benefits. ${ }^{2,3}$

Biomarkers, including the now well-established use of B-type natriuretic peptide (BNP) $)^{4,5}$ and more recently mid-regional pro-atrial natriuretic peptide (MR-proANP) ${ }^{6}$, have become key elements in the diagnosis of heart failure and are known to be strong predictors of morbidity (heart failure-hospitalisation or functional deterioration) and mortality, in turn acting as potential surrogate markers of prognosis. In addition to BNP and MR-proANP, Apelin ${ }^{7,8}$ and the inflammatory marker IL- $6^{9,10}$ may provide additional information on the progress of the heart failure syndrome. The effect of a rhythm-control versus rate-control strategy on these biomarkers, in the context of persistent atrial fibrillation and heart failure, is not clear.

In the recently reported ARC-HF study, a randomized clinical trial comparing catheter ablation with rate control for management of persistent atrial fibrillation in heart failure, we showed a beneficial impact of an ablation strategy upon cardiopulmonary exercise performance. ${ }^{11}$ In this pre-defined per-protocol analysis, we sought to examine the relative impact of ablation and rate-control on cardiac remodelling as evidenced by changes in MR- 
proANP, BNP, and Apelin, and whether there was an interaction with changes in inflammatory state, assessed by parallel measurement of IL-6.

\section{Methods}

\section{Study population}

Serial blood samples were acquired from patients enrolled in a randomized trial, ARC-HF (catheter Ablation versus Rate Control for management of persistent atrial fibrillation in Heart Failure, ClinicalTrials.gov NCT00878384) ${ }^{11}$ which tested the hypothesis that ablationbased rhythm-control improves outcomes compared to a conventional rate-control strategy, using exercise, questionnaire and image-based assessment of cardiovascular function as outcomes. The study complied with the Declaration of Helsinki, was approved by the local research ethics committee, and informed consent was obtained from all subjects.

The trial population consisted of patients with persistent (documented AF $>7$ days in duration) or permanent (persistent $\mathrm{AF}>1$ year) atrial fibrillation and chronic heart failure NYHA class $\geq \mathrm{II} ; \mathrm{LVEF} \leq 35 \%$. The strategies of rate control (target heart rate $\leq 80 \mathrm{bpm}$ at rest, and $\leq 110 \mathrm{bpm}$ at 6 minute walk) and catheter ablation were compared in a 1:1 randomised fashion, with primary endpoint of peak oxygen consumption at exercise testing, and secondary endpoints including ejection fraction, 6 minute walk, and Minnesota quality of life score.

\section{Sample acquisition}

Prior to exercise testing, peripheral venous blood was collected from patients in the resting state, into tubes containing $7 \mathrm{ml}$ ethylene-diamine-tetra-acetic acid. Centrifugation was performed at $1000 \mathrm{G}$ for 5 minutes, within 1 hour of sample acquisition, and plasma was extracted via manual pipette into cryo-tubes for freezer storage of $2 \mathrm{ml}$ plasma aliquots at -70 
degrees C. Samples were acquired at enrolment into the trial, and at subsequent follow-up visits at 3,6 and 12 months. Samples were thawed once and aliquots taken for all biomarker analyses.

\section{Laboratory assays and reference ranges}

Laboratory analyses were performed blinded to the randomisation group, using coded pseudo-anonymised labelling of samples. MR-proANP was measured by immunofluorescent assay on the Brahms Kryptor analyser (Thermo scientific, BRAHMS GmbH, Henningsdorf, Berlin, Germany; analytical range 2.1-10000 pmol/L). Previous studies have identified MRproANP levels in healthy individuals typically $<100 \mathrm{pmol} / \mathrm{L},{ }^{12} 120-130 \mathrm{pmol} / \mathrm{L}$ as a cut-off for the diagnosis of acute heart failure, ${ }^{13,14}$ and $>300 \mathrm{pmol} / \mathrm{L}$ as an independent prognostic marker in chronic heart failure. ${ }^{6} \quad B N P$ was measured by immunoassay on the Beckman Access 2 Immunoassay analyser (Beckman Coulter, High Wycombe, UK) using the Alere Triage BNP reagents (analytical range 25-5000pg/ml). This and similar BNP assays have a typical cut-off of $100 \mathrm{pg} / \mathrm{ml}$ for acute heart failure diagnosis, with levels $>300-400 \mathrm{pg} / \mathrm{ml}$ in significant heart failure and associated with worse prognostic outcome. ${ }^{15,16}$ Apelin was measured by ELISA (Phoenix Europe GmbH, Karlsruhe, Germany); an extraction-free protocol was followed. The antibody used in this apelin assay cross-reacts $100 \%$ with Apelin12, 13 and 36. The assay therefore includes all of the above peptides if present in the plasma (analytical range 0.01-100 ng/ml). Typical range in normal controls has been reported 20004000pg/ml. ${ }^{8,17} I L-6$ was measured by immunoassay on the Beckman Access 2 Immunoassay analyser (Beckman Coulter, High Wycombe, UK; analytical range 2.5-1500 pg/ml, reference range $<6.4 \mathrm{pg} / \mathrm{mL})$. 


\section{Statistical analysis}

In order to examine to impact of undergoing ablation, a per-protocol analysis was used, with censorship of results after any breach of protocol. The sample size was calculated for the primary endpoint of the pre-existing clinical trial, requiring 25 patients in each group to detect a $2 \pm 2.5 \mathrm{ml} / \mathrm{kg} / \mathrm{min}$ change in peak oxygen consumption at exercise testing. ${ }^{11}$ The magnitude of possible effect on Apelin and MR-ANP was unknown, however previous observational studies have examined changes in BNP after ablation in similar size populations. ${ }^{18,19}$ Assuming similar variability, our study population would be sufficient to detect a $20 \mathrm{pmol} / \mathrm{L}$ reduction in BNP at $80 \%$ power, two-sided alpha 0.05 .

Baseline values are expressed as mean (SD) for parametric data, median and interquartile range (IQR $=25^{\text {th }}$ to $75^{\text {th }}$ percentiles) for non-parametric data, or frequency/percentage as appropriate. The primary endpoint was change in biomarker plasma level at 12 months, and secondary endpoints were change at 3 and 6 months. Change was assessed by independent group comparison of individual absolute differences from baseline. Data were assessed for normality by histogram, skewness, and Kruskal-Wallis test within SPSS version 20 (IBM). Based upon this, normally distributed data were analysed by independent (two-sample) t-test (adjusted for presence/absence of equal variances by Levene's test) and presented as mean $\pm \mathrm{SD}$, whilst non-parametric data were analysed by Mann Whitney U (Wilcoxon ranksum) test and summarised as median (IQR). Paired t or Wilcoxon tests were used to analyse individual responses. Correlation analyses were performed using Pearson (parametric) or Spearman Rank (non-parametric) methods. Two-sided P values of less than 0.05 were regarded as statistically significant, and a p-value less than 0.1 was used as an indication of a non-significant trend. 


\section{Results}

A flow-chart illustrating the study protocol and follow-up is shown in Figure 1. A total of 52 patients were enrolled in the ARC-HF study. One patient withdrew consent for ablation and continued on normal medical therapy, and was excluded from the per-protocol analysis. Two patients had baseline and 3 month assays only: one entered palliative care for end stage heart failure post 3 month follow-up, was unable to attend 6 month follow-up and died prior to the final 12 month follow-up (biomarker results at these time-points also not being available in the original intention-to-treat analysis); another patient requested catheter ablation at 4 months and results were censored after 3 month follow-up. Consequently at 12 months, 25 rate control patients and 24 ablation patients were included for analysis, reduced by 2 patients compared with the equivalent analysis in the original study. Baseline characteristics for the analysed cohort are shown in Table 1. The groups were well-matched for age, gender, heart failure aetiology and clinical characteristics.

After a mean of $1.2 \pm 0.5$ ablation procedures, sinus rhythm was present in 22 out of $24(92 \%)$ patients at 12-month follow-up in the ablation arm. In the rate-control arm ate-control criteria were achieved in 23 out of $24(96 \%)$ of rate-control patients that remained in AF (1 was cardioverted to sinus rhythm by an ICD shock prior to final follow-up). Resting heart rate was not significantly different between groups at baseline (Table 1), nor at 12 months (ablation $68 \pm 7 \mathrm{bpm}$, rate control $72 \pm 14 \mathrm{bpm}, \mathrm{p}=0.24$ ).

Mid-regional atrial natriuretic peptide (MR-proANP)

Baseline values (Table 1) for both MR-proANP and BNP were increased above reference range, similar to prior studies of patients with NYHA II-III heart failure. ${ }^{6,16}$ In the ablation arm, there was a median change of $-79.6 \mathrm{pmol} / \mathrm{L}$ (IQR -186.2 to -12.7 ) at 3 months, -123.1 $\mathrm{pmol} / \mathrm{L}(-231.1$ to -13.6$)$ at 6 months, and $-106.0 \mathrm{pmol} / \mathrm{L}(-228.2$ to -60.6$)$ at 12 months. In 
the rate-control arm, there was median change of $-39.6 \mathrm{pmol} / \mathrm{L}$ (IQR -77.4 to -0.6 ) at 3 months, $-31.1(-112.9$ to +0.3$)$ at 6 months, and $-28.7(-69$ to +9.5$)$ at 12 months. In comparison with rate control, the reductions in the ablation arm were non-significant at 3 months $(0.277)$ and 6 months (0.119) but were significant by 12 months $(\mathrm{p}=0.028)$ (Figure 2$)$.

\section{B-type natriuretic peptide (BNP)}

Similarly BNP reduced over time in both catheter ablation and rate-control arms. After catheter ablation, BNP showed a change of $-90 \mathrm{pg} / \mathrm{ml}(\mathrm{IQR}-270$ to +8$)$ at 3 months, -112 $\mathrm{pg} / \mathrm{ml}(-380$ to -3$)$ at 6 months, and $-120 \mathrm{pg} / \mathrm{ml}(-285$ to +8$)$ at 12 months. Under rate control, the changes were $-26 \mathrm{pg} / \mathrm{ml}(\mathrm{IQR}-74$ to +22$)$ at 3 months, $-24 \mathrm{pg} / \mathrm{ml}(-84$ to +56$)$ at 6 months, and $-16 \mathrm{pg} / \mathrm{ml}(-88$ to +36$)$ at 12 months. Comparing the groups, the reduction in BNP in the ablation arm was not significant at 3 months $(\mathrm{p}=0.17)$ however showed a strong nonsignificant trend towards greater reduction post-ablation at $6(\mathrm{p}=0.052)$ and 12 months $(\mathrm{p}=0.051)$. The sequential change for plasma BNP is presented in Figure 3. It is noted that, under the original intention-to-treat protocol of the ARC-HF trial, the outcome for BNP did reach significance for a reduction with ablation over rate-control $(\mathrm{p}=0.038$ at 6 months and $\mathrm{p}=0.045$ at 12 months $)^{11}$ : the difference may reflect borderline power of the sample size, noting that the per-protocol analysed cohort was reduced by 2 patients at 6 and 12 months in comparison with the original.

\section{Apelin}

Baseline Apelin levels were lower than typical reference ranges, consistent with earlier data. ${ }^{8}$ In the ablation arm, median change was $-27 \mathrm{pg} / \mathrm{ml}(\mathrm{IQR}-250.25$ to +161.5$)$ at 3 months, $89.5 \mathrm{pg} / \mathrm{ml}(-238.5$ to +52.5$)$ at 6 months, and $+9.5 \mathrm{pg} / \mathrm{ml}(-153.5$ to +139.75$)$ at 12 months. By comparison, in the rate control arm, median change was +74.5 (IQR -65 to 205.25) at 3 months, $+133 \mathrm{pg} / \mathrm{ml}(-40$ to +240$)$ at 6 months, and $+120 \mathrm{pg} / \mathrm{ml}(-9$ to +294$)$ at 12 months. 
The difference in groups was non-significant at 3 months $(\mathrm{p}=0.22)$, although there was further change reaching significance at 6 months $(\mathrm{p}=0.002)$. However, following an overall increase in Apelin level in the final 6 months, comparison at 1 year was non-significant $(p=0.134)$. The sequential changes in plasma apelin are displayed graphically in Figure 4.

\section{Interleukin-6 (IL-6)}

Overall, average IL-6 levels around the upper reference value at baseline. In the catheter ablation group, IL-6 showed a median change of $+0.07 \mathrm{pg} / \mathrm{mL}$ (IQR -0.45 to +0.76 ) at 3 months, $+0.06 \mathrm{pg} / \mathrm{mL}$ (IQR -0.52 to +1.38 ) at 6 months, and $-0.06 \mathrm{pg} / \mathrm{mL}$ (IQR -0.64 to +1.69 ) at 12 months. In the rate control group, the change was $-0.1 \mathrm{pg} / \mathrm{mL}$ (IQR -0.89 to $0.51)$ at 3 months, $+0.11 \mathrm{pg} / \mathrm{mL}(\mathrm{IQR}-0.78$ to +0.88$)$ at 6 months, and $+0.34 \mathrm{pg} / \mathrm{mL}$ (IQR 0.47 to +0.87 ) at 12 months. Comparing the groups, there was no significant difference at 3 $(\mathrm{p}=0.93), 6(\mathrm{p}=0.32)$ or 12 months $(\mathrm{p}=0.68)$. Results for change in IL-6 from baseline are shown graphically in Figure 5.

\section{Correlation of biomarkers with ARC-HF endpoints}

The trends in change for MR-proANP and BNP following ablation, versus rate-control, were concordant with the change in peak VO2, quality of life score and left ventricular ejection fraction found in the ARC-HF trial. ${ }^{11}$ Correlation analysis (Table 2) showed that MRproANP correlated best with all 3 endpoints, and most closely correlated with peak VO2, whilst BNP correlated well with peak VO2 and better than the other biomarkers with change in LVEF. Change in both biomarkers correlated moderately with change in left atrial size. MR-proANP and BNP correlated well together (change at 12 months $\mathrm{R}=0.63, \mathrm{p}<0.001$ ). There were no significant correlations between Apelin or IL-6 and any of the original endpoints. 


\section{Discussion}

This study investigated the impact of catheter ablation-based rhythm control versus medical rate-control on cardiac and inflammatory biomarkers in patients with persistent $\mathrm{AF}$ and systolic heart failure. At 12 months, the resulting prevalence of sinus rhythm was nearly as high in the ablation group (92\%) as that of rate-controlled $\mathrm{AF}$ in the rate-control group (96\%). Hence the study examines not only strategy but also, effectively, the effect of sinus rhythm versus $\mathrm{AF}$ at follow-up.

The most significant impact was on MR-proANP, which showed an overall trend towards reduction in both groups, with significantly greater reduction in the ablation arm at 12 months. Whilst, atrial natriuretic peptide (ANP) proved to be inferior to BNP in terms of its diagnostic and prognostic potential, largely due to lack of reproducibility, the recently introduced assay of the mid-regional segment of its precursor, MR-proANP has recently been identified as an important biomarker, with several studies indicating its potential role as a predictor of morbidity and mortality. ${ }^{6,20}$ It has been shown to have similar accuracy to BNP as a diagnostic test, ${ }^{6}$ and may be a stronger prognostic marker. ${ }^{20}$ Additionally it may be superior to BNP for detecting and managing high-risk patients with chronic heart failure. ${ }^{16}$ Increases of $\geq 30 \%$ have appeared to define patients at highest risk of events, although more modest changes also have an impact. ${ }^{16}$ In the current study, the median reduction in MR-proANP after ablation was $28 \%$, compared with $7 \%$ for rate control at 12 months. Although in the current study, the potential prognostic implications are purely speculative, the finding that changes in MR-proANP correlate strongly with changes in $\mathrm{VO}_{2}$ (and moderately well with changes in LVEF and quality of life score) would further support the emerging evidence supporting use of this biomarker in assessing the impact of treatment and assisting risk stratification of patients with heart failure. ${ }^{16}$ The significant reduction in MR-pro-ANP over 10

This article is protected by copyright. All rights reserved. 
time may also suggest a favourable effect on atrial remodelling in addition to the presumed beneficial effects on LV structure and function.

Although it has been shown that MR-proANP levels are higher in non-heart failure patients with AF compared with those in normal sinus rhythm, ${ }^{21}$ and the change of rhythm itself might be regarded as one explanation for the observed fall and thus be a potential confounder, it should be noted that similar values were observed in those with heart failure regardless of rhythm ${ }^{21}$ and - like peak $\mathrm{VO}_{2}$ in the main ARC-HF trial ${ }^{11}$ - the change was not entirely explained by restoration of rhythm alone, being more marked at ( 6 and) 12 months than at 3 months despite the same overall rate of sinus rhythm maintenance. Therefore, although the early change may reflect a combination of rhythm-change and cardiac remodelling, later differences are unlikely to be explained by analysis of patients in different rhythms alone, and suggest progressive regression of the heart failure syndrome after restoration of sinus rhythm.

It has been shown that BNP and N-terminal pro-BNP levels are not independently affected by AF in advanced heart failure, ${ }^{22,23}$ thus BNP is well placed for assessing serial change in cardiac function. Notably, BNP levels have been shown to fall after catheter ablation for paroxysmal and persistent AF in patients without ventricular dysfunction. ${ }^{18,19}$ In the perprotocol analysis used in this biomarker study, the reduction in BNP showed a trend rather than reaching statistical significance as per the original intention-to-treat analysis, ${ }^{11}$ probably due to the effect of drop out. However, the changes in BNP observed in the present study showed similar trends to MR-proANP, and indeed the two measures were highly correlated. Furthermore, change in BNP correlated better than MR-proANP with change in LVEF, as expected given its relationship with ventricular strain and failure. 
IL-6, an inflammatory cytokine, has been shown to increase in patients with $\mathrm{AF},{ }^{24,25}$ may contribute to its pro-thrombotic state, ${ }^{26}$ and is increased acutely after ablation. ${ }^{27}$ IL-6 is also known to be raised in patients with chronic heart failure, ${ }^{10}$ and to be an independent predictor of mortality and worsening heart failure. ${ }^{28,29}$ Previous studies have shown a potential link between changes in inflammatory state and that of cardiac biomarkers including $\mathrm{BNP},{ }^{30}$ and there is limited evidence for IL-6 mediating upregulation of BNP during cardiac stress. ${ }^{31}$ In the present study, IL-6 did not show a significant elevation at baseline, change over time, or difference between groups at follow-up, and these findings suggest i) that ablation, beyond the acute post-operative period, has an apparently neutral effect on markers of inflammation in the context of pre-existing persistent AF and heart failure, and ii) that the changes in MRproANP and BNP are independent of a change in IL-6 - which may be reflective of the inflammatory state.

The relatively novel peptide apelin is an endogenous ligand with potent inotropic effects. ${ }^{32-34}$ Apelin levels are known to be reduced in patients with chronic heart failure when compared with controls ${ }^{8}$, and are raised by intervention such as biventricular pacing ${ }^{35}$ although other studies have shown that levels may be increased in mild-moderate heart failure, and decrease back towards control levels in severe heart failure. ${ }^{7}$ Apelin, perhaps as a consequence of this heterogeneity, is the most difficult of the biomarkers to interpret, both in terms of the results of this study and their clinical and pathophysiological relevance. In the presence of the latter pattern of behaviour, varied response to restoration of improved haemodynamics might be expected, with patients starting from different positions on the scale, and may be one explanation for the lack of a clear difference between Apelin levels in the two treatment arms. Furthermore, plasma Apelin itself may be an insufficient marker in isolation, without 
considering its binding interaction with the APJ receptor at the cardiac level, which appears to be down-regulated in heart failure and up-regulated during reverse ventricular remodelling. ${ }^{7}$

\section{Study Limitations}

This study used a per-protocol analysis, which may overestimate clinical effects from treatment strategies, although this protocol was pre-specified and sought to examine the real impact of catheter ablation rather than using an intention-to-treat analysis as was appropriate for the principal clinical trial outcomes. None of the biomarker data-sets were normally distributed, at least in part due the relatively small sample size, and therefore non-parametric testing was used: this limits conclusive comments to be made about the magnitude of change when comparing the treatment arms and precluded serial measures analysis by summary measures, including area-under-curve ${ }^{36}$ which is not pragmatically feasible without application of parametric testing. Analysis of change at 3 and 6 months (secondary endpoints) did not adjust for multiple comparisons and should be considered exploratory.

\section{Conclusion}

This study has shown, for the first time, that a catheter-ablation based rhythm control strategy, when compared with rate-control, significantly lowers MR-proANP at follow-up. BNP showed a similar trend, whilst there was no overall effect on Apelin or IL-6. The reduction in MR-proANP, and to a lesser extent BNP, correlated with improved cardiopulmonary, qualityof-life and imaging indices. Overall, these findings would suggest a beneficial effect of a catheter ablation strategy, unrelated to any demonstrable changes in the inflammatory state, with possible prognostic relevance that will require further evaluation in event-endpoint driven clinical trials. 


\section{Acknowledgements}

We are grateful to Helen Berry in the biochemistry laboratory at Royal Brompton Hospital for assisting with sample assays.

\section{Author Contributions}

D G Jones - conception and design of the study, acquisition of data, analysis and interpretation of data, statistical analysis, obtaining funding, drafting of the manuscript, critical revision of article, final approval of the manuscript; S K Haldar - acquisition of data, critical revision of article, final approval; J Donovan - acquisition of data, analysis and interpretation of the data, critical revision of article, final approval; T A McDonagh conception and design of the research, critical revision of article, final approval; R Sharma conception and design of the research, critical revision of the article, final approval; W Hussain - drafting of the manuscript, critical revision of the article, final approval; V Markides - conception and design of the research, obtaining funding, critical revision of the article, supervision, final approval; T Wong - conception and design of the research, obtaining funding, drafting of the manuscript, critical revision of the article, supervision, final approval

\section{References}

1. Roy D, Talajic M, Nattel S, Wyse DG, Dorian P, Lee KL, Bourassa MG, et al. Rhythm control versus rate control for atrial fibrillation and heart failure. N Engl J Med. 2008;358:2667-77.

2. Hsu LF, Jais P, Sanders P, Garrigue S, Hocini M, Sacher F, Takahashi Y, et al. Catheter ablation for atrial fibrillation in congestive heart failure. N Engl J Med. 2004;351:2373-83.

3. Chen MS, Marrouche NF, Khaykin Y, Gillinov AM, Wazni O, Martin DO, Rossillo A, et al. Pulmonary vein isolation for the treatment of atrial fibrillation in patients with impaired systolic function. J Am Coll Cardiol. 2004;43:1004-9. 
4. Gheorghiade M, Adams KF, Jr., Gattis WA, Teerlink JR, Orlandi C, O'Connor CM. Surrogate end points in heart failure trials. Am Heart J. 2003;145:S67-70.

5. Gardner RS, Ozalp F, Murday AJ, Robb SD, McDonagh TA. N-terminal pro-brain natriuretic peptide: A new gold standard in predicting mortality in patients with advanced heart failure. Eur Heart J. 2003;24:1735-43.

6. von Haehling S, Jankowska EA, Morgenthaler NG, Vassanelli C, Zanolla L, Rozentryt $P$, Filippatos GS, et al. Comparison of midregional pro-atrial natriuretic peptide with $\mathrm{N}$-terminal pro-B-type natriuretic peptide in predicting survival in patients with chronic heart failure. $J$ Am Coll Cardiol. 2007;50:1973-80.

7. Chen MM, Ashley EA, Deng DXF, Tsalenko A, Deng A, Tabibiazar R, Ben-Dor A, et al. Novel Role for the Potent Endogenous Inotrope Apelin in Human Cardiac Dysfunction. Circulation. 2003;108:1432-9.

8. Chong KS, Gardner RS, Morton JJ, Ashley EA, McDonagh TA. Plasma concentrations of the novel peptide apelin are decreased in patients with chronic heart failure. Eur J Heart Fail. 2006;8:355-60.

9. Birks EJ, Latif N, Owen V, Bowles C, Felkin LE, Mullen AJ, Khaghani A, et al. Quantitative myocardial cytokine expression and activation of the apoptotic pathway in patients who require left ventricular assist devices. Circulation. 2001;104:1233-40.

10. Wollert KC, Drexler H. The role of interleukin-6 in the failing heart. Heart Fail Rev. 2001;6:95103.

11. Jones DG, Haldar SK, Hussain W, Sharma R, Francis DP, Rahman-Haley SL, McDonagh TA, et al. A randomized trial to assess catheter ablation versus rate control in the management of persistent atrial fibrillation in heart failure. J Am Coll Cardiol. 2013;61:1894-903.

12. Morgenthaler NG, Struck J, Thomas B, Bergmann A. Immunoluminometric assay for the midregion of pro-atrial natriuretic peptide in human plasma. Clin Chem. 2004;50:234-6.

13. Gegenhuber A, Struck J, Poelz W, Pacher R, Morgenthaler NG, Bergmann A, Haltmayer M, et al. Midregional pro-A-type natriuretic peptide measurements for diagnosis of acute destabilized heart failure in short-of-breath patients: comparison with B-type natriuretic peptide (BNP) and amino-terminal proBNP. Clin Chem. 2006;52:827-31.

14. Maisel A, Mueller C, Nowak R, Peacock WF, Landsberg JW, Ponikowski P, Mockel M, et al. Mid-region pro-hormone markers for diagnosis and prognosis in acute dyspnea: results from the BACH (Biomarkers in Acute Heart Failure) trial. J Am Coll Cardiol. 2010;55:2062-76.

15. Maisel A. B-Type Natriuretic Peptide Levels: Diagnostic and Prognostic in Congestive Heart Failure: What's Next? Circulation. 2002;105:2328-31.

This article is protected by copyright. All rights reserved. 
16. Miller WL, Hartman KA, Grill DE, Struck J, Bergmann A, Jaffe AS. Serial measurements of midregion proANP and copeptin in ambulatory patients with heart failure: incremental prognostic value of novel biomarkers in heart failure. Heart. 2012;98:389-94.

17. Weir RA, Chong KS, Dalzell JR, Petrie CJ, Murphy CA, Steedman T, Mark PB, et al. Plasma apelin concentration is depressed following acute myocardial infarction in man. Eur J Heart Fail. 2009;11:551-8.

18. Yamada T, Murakami Y, Okada T, Okamoto M, Shimizu T, Toyama J, Yoshida Y, et al. Plasma atrial natriuretic Peptide and brain natriuretic Peptide levels after radiofrequency catheter ablation of atrial fibrillation. Am J Cardiol. 2006;97:1741-4.

19. Sacher F, Corcuff J-B, Schraub P, Le Bouffos V, Georges A, Jones SO, Lafitte S, et al. Chronic atrial fibrillation ablation impact on endocrine and mechanical cardiac functions. Eur Heart J. 2008;29:1290-5.

20. Moertl D, Berger R, Struck J, Gleiss A, Hammer A, Morgenthaler NG, Bergmann A, et al. Comparison of midregional pro-atrial and B-type natriuretic peptides in chronic heart failure: influencing factors, detection of left ventricular systolic dysfunction, and prediction of death. J Am Coll Cardiol. 2009;53:1783-90.

21. Eckstein J, Potocki M, Murray K, Breidthardt T, Ziller R, Mosimann T, Klima T, et al. Direct comparison of mid-regional pro-atrial natriuretic peptide with $\mathrm{N}$-terminal pro B-type natriuretic peptide in the diagnosis of patients with atrial fibrillation and dyspnoea. Heart. 2012;98:1518-22.

22. Rossi A, Enriquez-Sarano M, Burnett JC, Jr., Lerman A, Abel MD, Seward JB. Natriuretic peptide levels in atrial fibrillation: a prospective hormonal and Doppler-echocardiographic study. J Am Coll Cardiol. 2000;35:1256-62.

23. Rienstra M, Van Gelder IC, Van den Berg MP, Boomsma F, Van Veldhuisen DJ. Natriuretic peptides in patients with atrial fibrillation and advanced chronic heart failure: determinants and prognostic value of (NT-)ANP and (NT-pro)BNP. Europace. 2006;8:482-7.

24. Marcus GM, Whooley MA, Glidden DV, Pawlikowska L, Zaroff JG, Olgin JE. Interleukin-6 and atrial fibrillation in patients with coronary artery disease: data from the Heart and Soul Study. Am Heart J. 2008;155:303-9.

25. Marcus GM, Smith LM, Ordovas K, Scheinman MM, Kim AM, Badhwar N, Lee RJ, et al. Intracardiac and extracardiac markers of inflammation during atrial fibrillation. Heart Rhythm. 2010;7:149-54.

26. Conway DS, Buggins P, Hughes E, Lip GY. Relationship of interleukin- 6 and C-reactive protein to the prothrombotic state in chronic atrial fibrillation. J Am Coll Cardiol. 2004;43:2075-82. 
27. Stein A, Wessling G, Deisenhofer I, Busch G, Steppich B, Estner H, Zrenner B, et al. Systemic inflammatory changes after pulmonary vein radiofrequency ablation do not alter stem cell mobilization. Europace. 2008;10:444-9.

28. Maeda K, Tsutamoto T, Wada A, Mabuchi N, Hayashi M, Tsutsui T, Ohnishi M, et al. High levels of plasma brain natriuretic peptide and interleukin- 6 after optimized treatment for heart failure are independent risk factors for morbidity and mortality in patients with congestive heart failure. J Am Coll Cardiol. 2000;36:1587-93.

29. Gwechenberger M, Hulsmann M, Berger R, Graf S, Springer C, Stanek B, Pacher R. Interleukin-6 and B-type natriuretic peptide are independent predictors for worsening of heart failure in patients with progressive congestive heart failure. J Heart Lung Transplant. 2004;23:839-44.

30. Ma KK, Ogawa T, de Bold AJ. Selective upregulation of cardiac brain natriuretic peptide at the transcriptional and translational levels by pro-inflammatory cytokines and by conditioned medium derived from mixed lymphocyte reactions via p38 MAP kinase. J Mol Cell Cardiol. 2004;36:505-13.

31. Xia WJ, Huang YY, Chen YL, Chen SL, He JG. Acute myocardial ischemia directly modulates the expression of brain natriuretic peptide at the transcriptional and translational levels via inflammatory cytokines. Eur J Pharmacol. 2011;670:7-12.

32. O'Dowd BF, Heiber M, Chan A, Heng HH, Tsui LC, Kennedy JL, Shi X, et al. A human gene that shows identity with the gene encoding the angiotensin receptor is located on chromosome 11. Gene. 1993;136:355-60.

33. Berry MF, Pirolli TJ, Jayasankar V, Burdick J, Morine KJ, Gardner TJ, Woo YJ. Apelin has in vivo inotropic effects on normal and failing hearts. Circulation. 2004;110:I1187-93.

34. Ashley EA, Powers J, Chen M, Kundu R, Finsterbach T, Caffarelli A, Deng A, et al. The endogenous peptide apelin potently improves cardiac contractility and reduces cardiac loading in vivo. Cardiovasc Res. 2005;65:73-82.

35. Francia P, Salvati A, Balla C, De Paolis P, Pagannone E, Borro M, Gentile G, et al. Cardiac resynchronization therapy increases plasma levels of the endogenous inotrope apelin. Eur J Heart Fail. 2007;9:306-9.

36. Matthews JN, Altman DG, Campbell MJ, Royston P. Analysis of serial measurements in medical research. BMJ. 1990;300:230-5.

This article is protected by copyright. All rights reserved. 


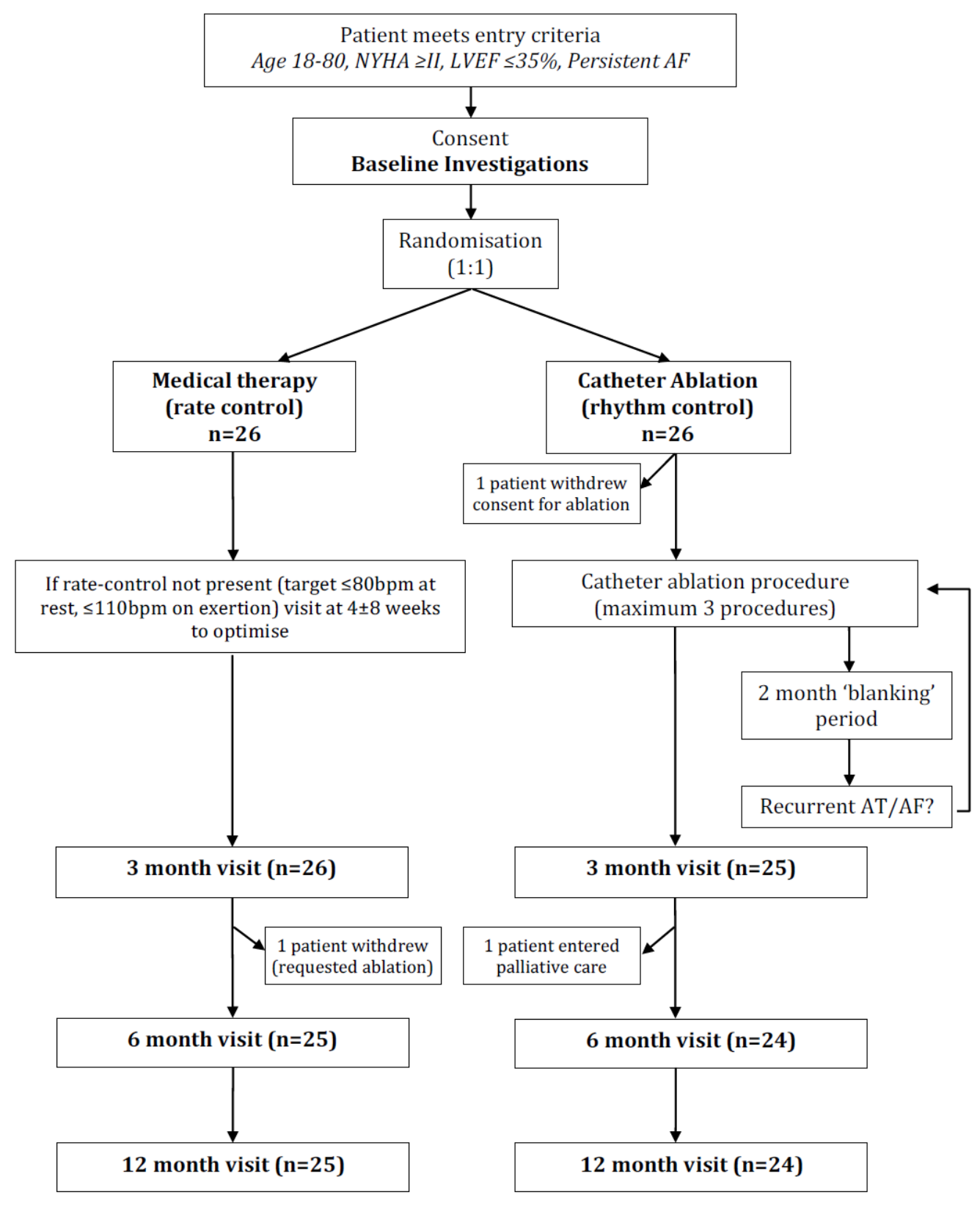

Figure 1 ARCHF-biomarker study flowchart.

Number of patients included for per-protocol analysis shown at each time point

This article is protected by copyright. All rights reserved. 


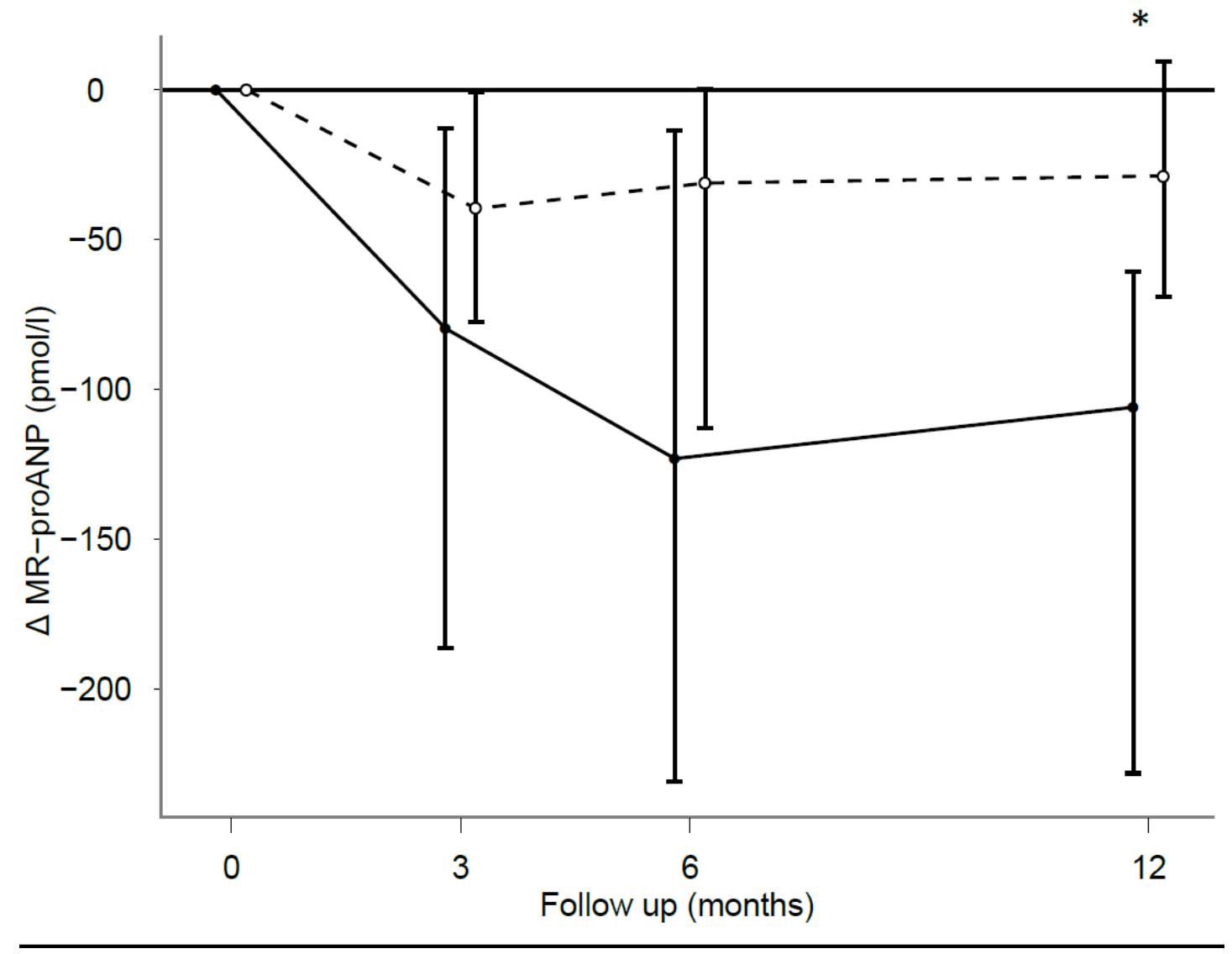

Figure 2 Mid-Regional proAtrial Natriuretic Peptide (MR-proANP)

Change $(\Delta)$ in mid-regional proANP (MR-proANP) from baseline at follow-up, represented as median with error bars showing $25^{\text {th }}$ and $75 \mathrm{~h}$ percentiles (IQR): catheter ablation (solid line) vs. rate control (dashed line). Statistical significance* is shown at 12 months between groups $(p=0.028)$

This article is protected by copyright. All rights reserved. 


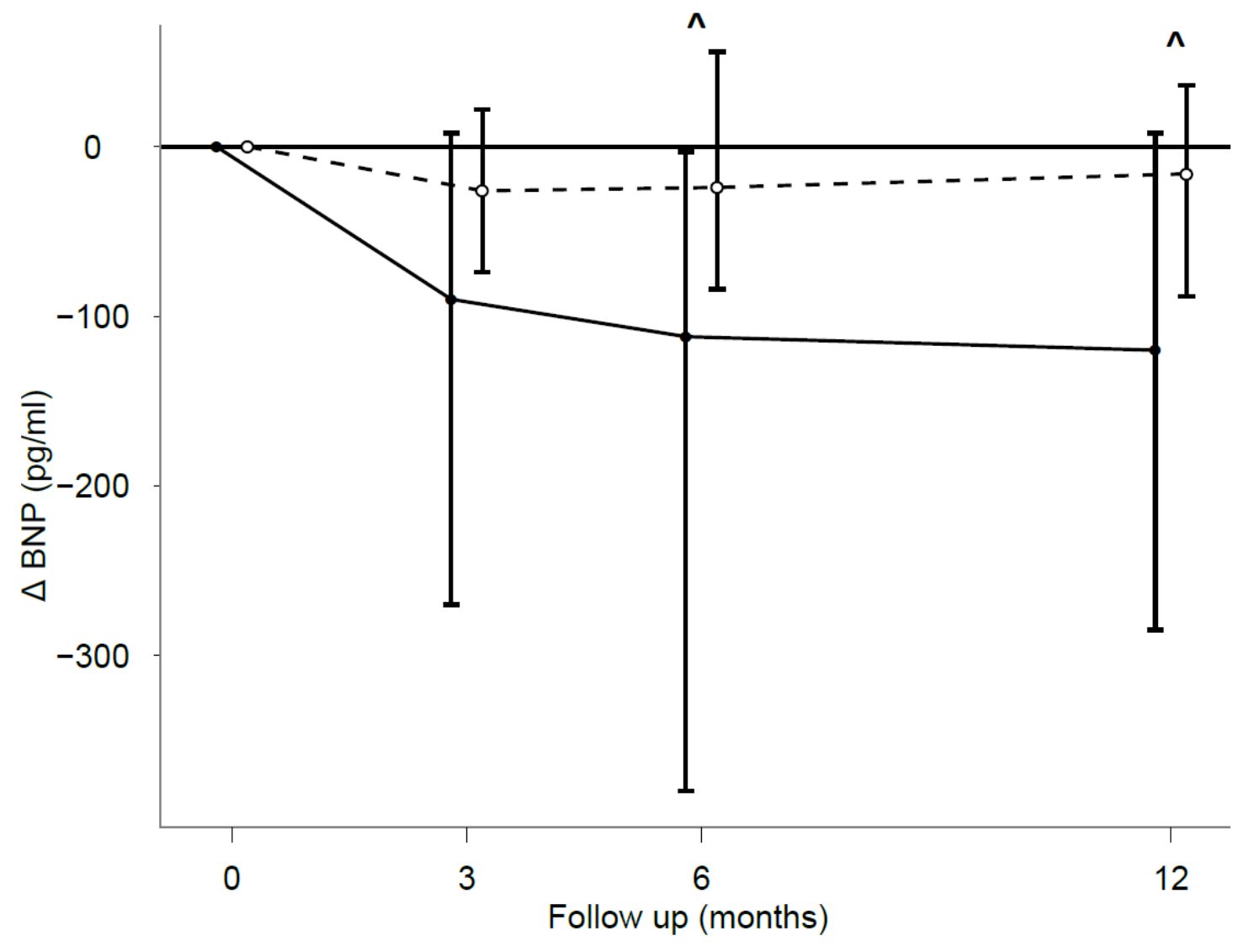

Figure 3 B-type Natriuretic Peptide (BNP)

Change $(\Delta)$ in BNP from baseline at follow-up time points, represented as median with error bars showing IQR: catheter ablation (solid line) vs. rate control (dashed line). The change at $6(p=0.052)$ and 12 months $(0.051)$ was borderline, showing a statistical trend^ ${ }^{\wedge}$ rather than meeting significance criteria.

This article is protected by copyright. All rights reserved. 


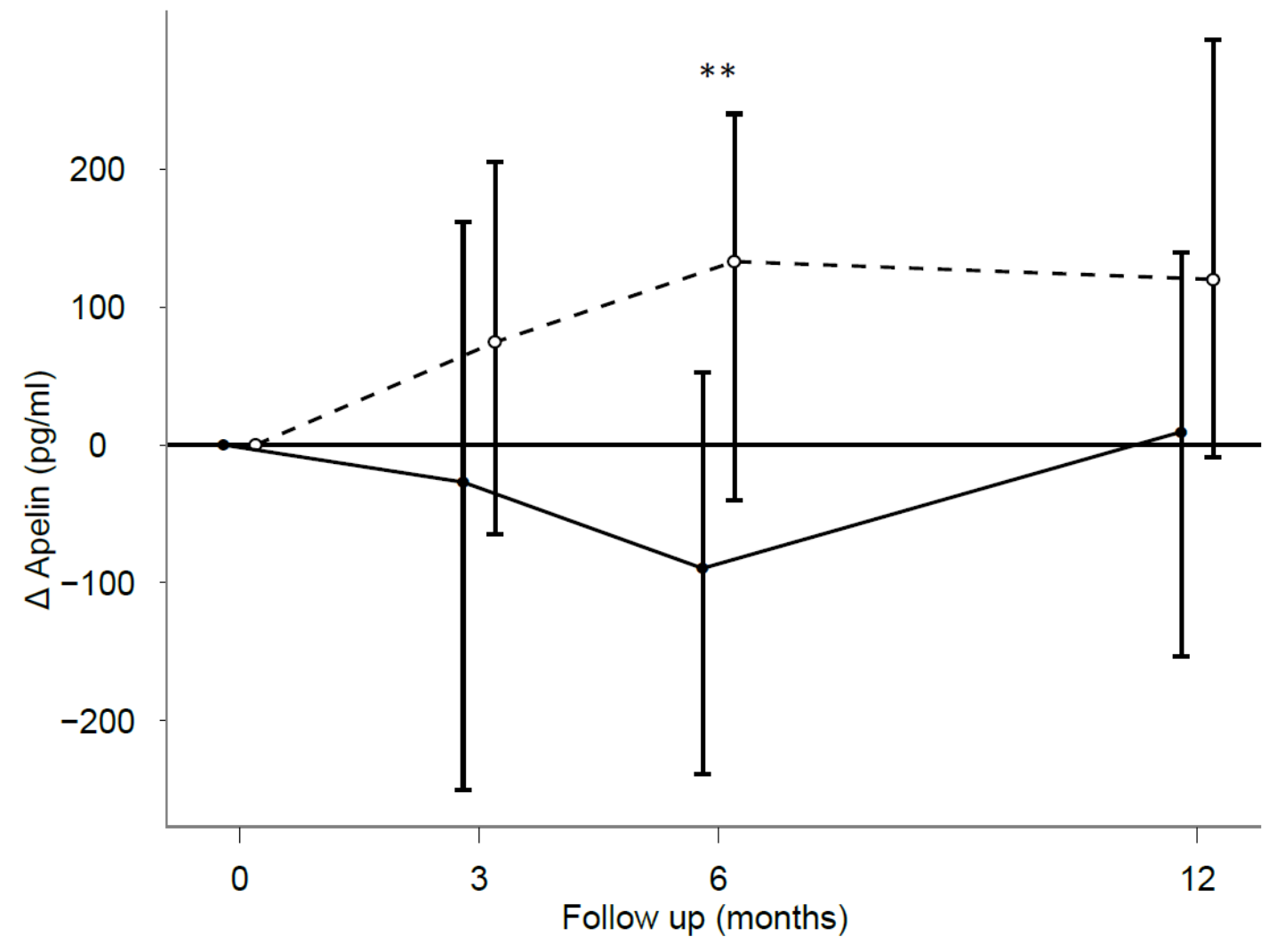

Figure 4 Apelin

Change $(\Delta)$ in Apelin from baseline at follow-up time points, represented as median with error bars showing IQR: catheter ablation (solid line) vs. rate control (dashed line). ** indicates $p=0.002$ at 6 months, whereas the difference between groups was not statistically significant at 12 months

This article is protected by copyright. All rights reserved. 


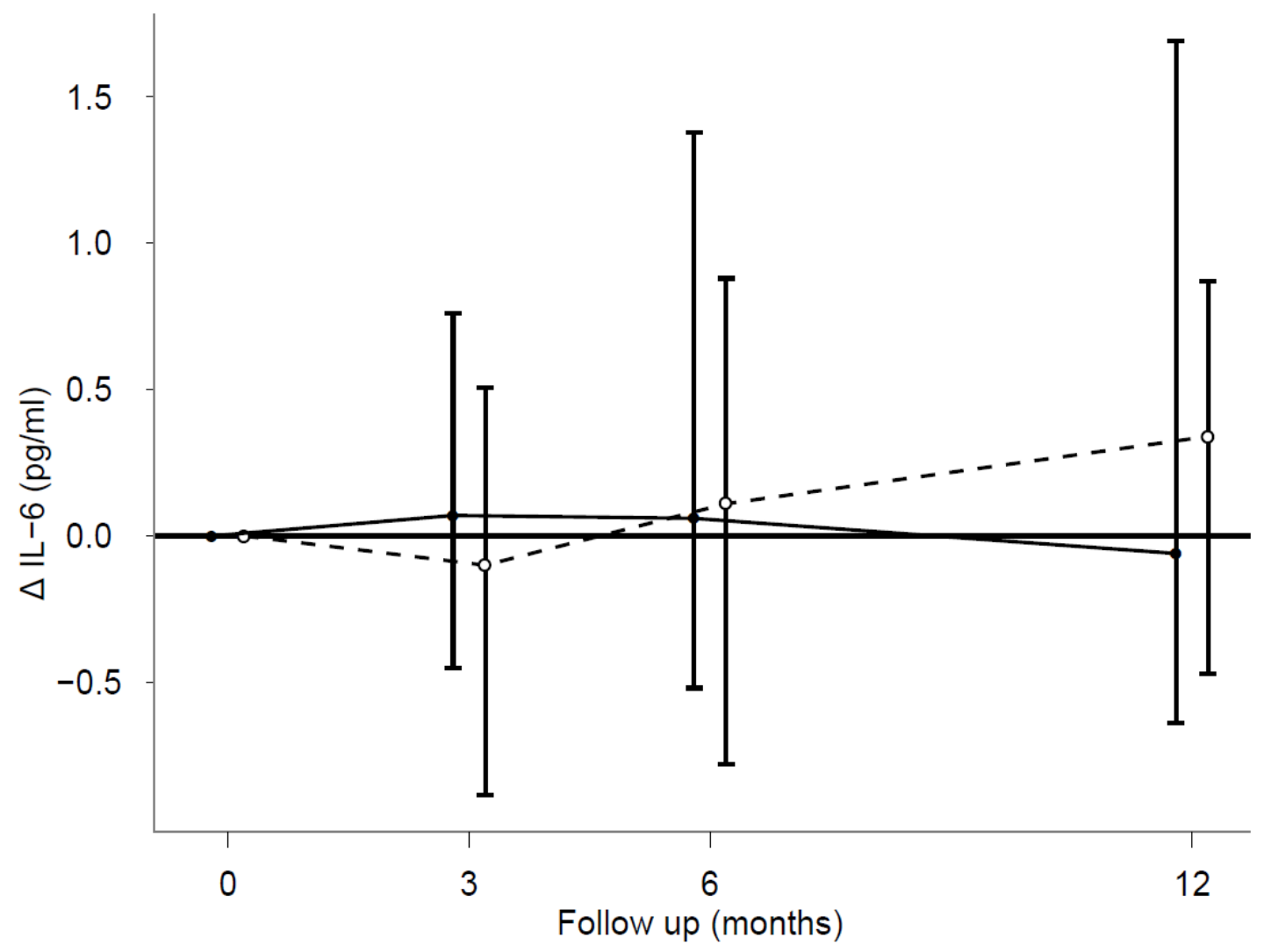

Figure 5 Interleukin-6 (IL-6)

Change $(\Delta)$ in IL-6 from baseline at follow-up time points, represented as median with error bars showing IQR: catheter ablation (solid line) vs. rate control (dashed line).

This article is protected by copyright. All rights reserved. 


\begin{tabular}{|c|c|c|c|}
\hline & $\begin{array}{c}\text { Rate control } \\
\quad n=25\end{array}$ & $\begin{array}{l}\text { Catheter Ablation } \\
n=24\end{array}$ & $p$ value \\
\hline & $\begin{array}{c}\mathrm{N}(\%) / \\
\text { mean } \pm \mathrm{SD}\end{array}$ & $\mathrm{N}(\%) /$ mean $\pm \mathrm{SD}$ & \\
\hline Age & $62 \pm 9$ & $64 \pm 10$ & 0.56 \\
\hline Male & $23(92)$ & $19(79)$ & 0.19 \\
\hline Ischaemic HF aetiology & $6(24)$ & $10(42)$ & 0.19 \\
\hline Time since HF diagnosis (months) & $49 \pm 58$ & $63 \pm 62$ & 0.40 \\
\hline Time since AF diagnosis (months) & $53 \pm 77$ & $49 \pm 37$ & 0.84 \\
\hline Duration of continuous AF (months) & $24 \pm 30$ & $23 \pm 22$ & 0.81 \\
\hline NYHA class & $2.5 \pm 0.5$ & $2.5 \pm 0.5$ & 0.88 \\
\hline NYHA I/ & $13(52)$ & $13(54)$ & \\
\hline NYHA III & $12(48)$ & $11(46)$ & \\
\hline Recent HF hospitalisation (<1year) & $7(28)$ & $8(33)$ & 0.69 \\
\hline Minnesota LHFQ score (/105) & $49 \pm 21$ & $42 \pm 22$ & 0.26 \\
\hline Creatinine $(\mu \mathrm{mol} / \mathrm{L})$ & $103 \pm 28$ & $95 \pm 23$ & 0.30 \\
\hline Peak $\mathrm{VO}_{2}(\mathrm{ml} / \mathrm{kg} / \mathrm{min})$ & $18.3 \pm 4.9$ & $16.5 \pm 5.5$ & 0.23 \\
\hline
\end{tabular}

This article is protected by copyright. All rights reserved. 
QRS duration (ms) non-paced only

Radionuclide LVEF (\%)

LA area (apical 4-chamber, $\mathrm{cm}^{2}$ )

6MWD $(\mathrm{m})$

Resting HR (bpm)

Exercise HR (bpm)

Proportion rate-controlled at baseline ( $\leq 80$ rest, $\leq 110$

at $6 \mathrm{MW})$

Beta blocker

ACE or ARB

Aldosterone antagonist

Amiodarone

Digoxin

Preexisting ICD; of which CRT

Biomarker baseline values

Apelin (pg/ml)

$\mathrm{BNP}(\mathrm{pg} / \mathrm{ml})$
$114 \pm 21$

$119 \pm 19$

0.45

$25 \pm 7$

$22 \pm 8$

0.21

$27 \pm 7$

$30 \pm 6$

0.15

$412 \pm 111$

$416 \pm 81$

0.88

$81 \pm 12$

$78 \pm 9$

0.31

$109 \pm 18$

$109 \pm 16$

0.94

14 (56)

$15(62)$

0.64

$23(92)$

$22(92)$

0.63

25 (100)

23 (96)

0.49

$5(20)$

$12(50)$

0.04

$3(12)$

$12(48)$

$14(58)$

0.47

4 (15); 3 (12)

9 (38); 7 (31)

0.08 ;

$1(4)$

1 (4)

0.51

$867 \pm 425$

$813 \pm 289$

0.61

$288 \pm 290$

$386 \pm 301$

0.25

This article is protected by copyright. All rights reserved. 
$\mathrm{ACE}=$ angiotensin converting enzyme inhibitor, $\mathrm{ARB}=$ angiotensin receptor blocker, $\mathrm{CRP}=\mathrm{C}$ reactive protein, $\mathrm{CRT}=$ cardiac resynchronization therapy, $\mathrm{HF}=$ heart failure, $\mathrm{HR}=$ heart rate, $\mathrm{ICD}=$ implantable cardioverter defibrillator, LHFQ $=$ Minnesota Living with Heart Failure Questionnaire, LVEF = left ventricular ejection fraction, NYHA $=$ New York Heart Association, 6MWD $=6$-minute walk distance.

This article is protected by copyright. All rights reserved. 
Table 2 Correlation of biomarkers with ARC-HF endpoints

\begin{tabular}{ccccccccc}
\hline & $\Delta$ MRANP & & $\Delta$ Apelin & & $\Delta$ BNP & & $\Delta \mathrm{lL}-6$ & \\
& $\mathrm{n}=49$ & $p$ & $\mathrm{n}=49$ & $p$ & $\mathrm{n}=48$ & $p$ & $\mathrm{n}=49$ & \\
\hline & & & & & & & & \\
$\Delta$ VO $_{2}$ & -0.68 & $<0.001$ & 0.13 & 0.36 & -0.63 & $<0.001$ & $0.01^{*}$ & 0.93 \\
& & & & & & & & \\
$\Delta$ LHFQ & 0.35 & 0.015 & 0.14 & 0.30 & 0.22 & 0.14 & -0.04 & 0.77 \\
$\Delta$ LVEF & -0.32 & 0.025 & -0.16 & 0.28 & -0.53 & $<0.001$ & $0.18^{*}$ & 0.23 \\
$\Delta$ LAa & 0.42 & 0.003 & 0.04 & 0.77 & 0.43 & 0.002 & $0.01^{*}$ & 0.93
\end{tabular}

For each biomarker correlation estimations were performed, using Spearman Rank (or *Pearson) correlation, against change $(\Delta)$ from baseline to 12 months follow-up, based on the per-protocol analysis (see Methods). Correlation coefficient values $(R)$ are shown with corresponding 2-sided $p$-values; $n=$ number of patients samples available for analysis

$B N P=B$-type natriuretic peptide, IL-6 - Interleukin-6, LAa = left atrial area (apical 4 chamber) $L H F Q=$ Minnesota Living with Heart Failure Questionnaire score, LVEF = left ventricular ejection fraction, $M R A N P=$ midregional pro-atrial natriuretic peptide, $V O 2=$ peak oxygen consumption at cardiopulmonary exercise test

This article is protected by copyright. All rights reserved. 